\title{
Combustion and emissions characteristics of a dual fuel engine operated on alternative gaseous
}

fuels

Nirendra N, Mustafi ${ }^{1 a}$, Robert R. Raine ${ }^{\mathrm{b}}$ and Sebastian Verhelst ${ }^{\mathrm{c}}$

${ }^{a}$ Dept. of Mechanical Engineering, Rajshahi University of Engineering \& Technology, Rajshahi, Bangladesh

${ }^{\mathrm{b}}$ Dept. of Mechanical Engineering, The University of Auckland, Private Bag 92019, Auckland, New Zealand

${ }^{\mathrm{c} D e p t . ~ o f ~ F l o w, ~ H e a t ~ a n d ~ C o m b u s t i o n ~ M e c h a n i c s, ~ G h e n t ~ U n i v e r s i t y, ~ B e l g i u m ~}$

\begin{abstract}
Among the different efforts towards the reduction in pollutant emissions from direct injection (DI) diesel engines, the use of gaseous fuels as a partial supplement for diesel fuel has been proposed by many researchers. These engines are known as dual fuel engines. An experimental investigation was performed to investigate the influence of dual-fuel combustion on the performance and exhaust emissions of a DI diesel engine fueled with natural gas (NG) and biogas. In this work, the combustion pressure and the rate of heat release were evaluated experimentally in order to analyze the combustion characteristics and their effects on exhaust emissions including particulate matter (PM) for single-fuel (diesel) and dual fuel combustion modes. The use of NG as an alternative fuel is a promising solution. Biogas, on the other hand, is a renewable alternative fuel that has tremendous potential to be used in diesel engines especially in developing nations. Comparative results are presented revealing the effect of dual fuel combustion on engine performance and exhaust gaseous and PM emissions for the engine operating conditions considered in this study.
\end{abstract}

Key Words: Dual fuel engine; Biogas; Combustion; Gaseous emissions; Particulate emissions.

\section{Introduction}

The use of diesel engines as reliable and fuel efficient sources of power for the transportation of goods and people and for other critical needs of society including small capacity power generation, has steadily grown over the past century. In many cases they are preferable due to their high thermal

\footnotetext{
${ }^{1}$ Corresponding author. Tel. +88-0721-750742-229

E-mail address: nnmustafi@yahoo.com (N. Mustafi)
} 
efficiency, and low regulated emissions of unburned hydrocarbons (HC), carbon monoxide (CO) and carbon dioxide $\left(\mathrm{CO}_{2}\right)$ compared to those of spark ignition engines [1,2]. The other important advantage of diesel engines is that they can operate at higher compression ratios, which permit them to use low energy-content alternative fuels such as biogas. However, diesel engines emit harmful pollutants including oxides of nitrogen $\left(\mathrm{NO}_{\mathrm{x}}\right)$ and particulate matter $(\mathrm{PM})$. That exhaust is of concern because of its impact on visibility and for its potential health hazards. Particulate emissions can be classified as potential occupational carcinogen and can have a number of other negative health impacts associated with exposure [3-6]. It is generally agreed that diesel engines used in transport systems represent an important source of ambient particulate matter [7]. These concerns are reflected in increasingly more stringent regulations to limit engine emissions. In response to the stringent regulations, the manufacturers of diesel engines and refiners of diesel fuel have made revolutionary advances in diesel technology including improved engines, exhaust after-treatment and use of improved, ultra-low sulfur fuels. The PM concentration in newer engines is remarkably lower than in older engines. It is clear that there have been tremendous advances in the control of diesel exhaust emissions in response to progressively more stringent regulations. However, especially in poor and developing nations, the use of older diesel engines without any after-treatment facility will still be dominating and thus the blessings of new technologies will remain unattainable there. Therefore, the reduction of exhaust emissions from such older diesel engines is an ongoing concern that needs to be addressed.

On the other hand, in recent years, the fossil-fuels have suffered from a sudden rise in prices because of the limitations of reserves, supply and considerable increases in demand for petroleum fuels resulting from the industrialization. Again, this is also a growing concern for the developing nations as they expend a significant part of their national income to import the petroleum products every year. Addressing the above concerns, researchers around the world are searching for alternative fuels for engines. Bio-fuels (liquid and gaseous) have been subject to intensive research work globally because of their attractive behaviors in combustion and emissions $[1,8]$. 
Gaseous fuels in diesel engines operate in dual fuel mode where the main energy comes from the gaseous fuel (known as primary fuel) and the minimum amount of liquid fuel such as diesel (known as pilot fuel) acts as the ignition source. Biogas is a mixture of gases produced during the biological breakdown of organic matter (such as agricultural wastes, animal organic waste, sewage treatment sludge or food processing wastes) in the absence of air. Biogas can also be obtained from anaerobic fermentation of organic waste in landfills [9]. Being a renewable gaseous fuel, biogas has the potential to supplement the use of diesel fuel in engines that are used for transportation, irrigation and non-grid power generation purposes. This is especially important in the case of developing countries where meeting the growing demand of fossil fuels is a major economic challenge. The use of biogas has twofold benefits: it provides an alternative source of energy and protects the environment from the harmful greenhouse gas, methane $\left(\mathrm{CH}_{4}\right)$ that would otherwise be emitted into the atmosphere [10]. Biogas is composed mostly of $\mathrm{CH}_{4}(50-70 \%)$ and $\mathrm{CO}_{2}(25-50 \%)$, with low fractions of $\mathrm{H}_{2}(1-5 \%)$, $\mathrm{N}_{2}(0.3-3 \%)$, and hydrogen sulfide $\left(\mathrm{H}_{2} \mathrm{~S}\right)$ traces [11]. Natural gas can be considered as another alternative fuel for diesel engines as many parts around the world including developing nations have access to the reserves.

Numerous research works on experimental and theoretical investigations concerning the dual fuel diesel-natural gas operating mode have been reported over the last decades in the literature [12-18]. On the other hand, a comparatively lower number of research works on biogas-diesel dual fuel engines are found. The past investigations concentrated mainly on the performance and fuel consumption characteristics for biogas-diesel dual fuel engines. Combustion characteristics and performance and emissions analyses were performed by Karim and Amoozegar [19] and Karim and Weirzba [20] for biogas-diesel dual fuel engine. However, their studies are mainly limited to part load or low load conditions. Mustafi and Raine [21] studied emissions from a dual fuel engine fuelled with NG and biogas; however, dual fuel combustion characteristics and their effects on emissions were not presented there. Recent efforts using biogas-biodiesel in dual fuel application are found in the references [22-24], or biogas application in HCCI engine [25]; where engine performance, combustion and emission characteristics are investigated. Although there are researches on the 
combustion and emission characteristics of biogas-diesel/biodiesel in dual-fuel concept, it is necessary to investigate into more detail the reduction characteristics of exhaust emissions and the combustion performance of the biogas-diesel dual-fuel engine in order to establish biogas as an alternative fuel for stationary older diesel engines. The objective of this study was to investigate the combustion characteristics of a diesel engine fueled with biogas and natural gas, in dual fuel mode, and the influence of dual fuel combustion on the exhaust emissions, with special attention to the PM emissions. Natural gas was used here as a datum or reference fuel as its data are well established in the literature. All the results thus obtained, were compared between different engine fueling conditions.

\section{Experimental setup and methodology}

The experiments that form the basis of the results presented here were conducted in the Thermodynamics Laboratory, at The University of Auckland, New Zealand. The base engine for this research was a Lister Petter PHW1, single cylinder, four-stroke, direct injection (DI), stationary diesel engine. The major engine specifications are given in Table 1 . The engine was modified to run on dual fuel mode and its original fuel injection system was maintained for the dual fuel operation. The engine modification for dual fueling, and all the required measurement systems including gaseous emissions and PM (gravimetric method); the properties of diesel and composition of pipeline NG etc. were described in detail elsewhere in [21]. Compressed $\mathrm{NG}$ and $\mathrm{CO}_{2}$ were mixed in the laboratory to obtain biogas mixtures such as biogas-1 $\left(80 \% \mathrm{CH}_{4} \& 20 \% \mathrm{CO}_{2}\right)$; biogas-2 $\left(67 \% \mathrm{CH}_{4} \& 33 \% \mathrm{CO}_{2}\right)$ and biogas-3 $\left(58 \% \mathrm{CH}_{4} \& 42 \% \mathrm{CO}_{2}\right)$. The total experimental setup can be found in [21].

Cylinder pressure was measured by a Kistler 601A piezoelectric transducer connected to a Kistler 5011 charge amplifier. The engine crankshaft was equipped with a disk having 360 teeth on its circumference. A top dead center (TDC) detector close to the disk detected each tooth or crank angle (CA) to ensure 360 pulses output per revolution of the crank shaft irrespective of engine speed. Data were recorded by a computer based high-speed data acquisition system. 
PM mass emissions were measured by the conventional gravimetric method and by a light scattering photometer (LSP) which involved the measurement of light intensity scattered by the particles and provided real time particulate mass concentration measurement. The LSP used in this study was a commercially available, direct-reading PM monitor, Dusttrak ${ }^{\mathrm{TM}}$ (DT) Aerosol Monitor (Model 8520, TSI Inc.). With appropriate calibration the LSP can show good potential as an online PM concentration measurement instrument and can provide comparable results with respect to the filter method [26]. A single stage partial flow dilution system (PFDS) was used in this study to dilute the representative exhaust gas sample drawn from the engine for PM measurements. The dilution ratio (DR) was maintained at approximately 10 to 1 for the whole experimental program and was monitored by measuring concentrations of $\mathrm{CO}_{2}$ in the raw and diluted sample.

Tests were performed at a constant speed of $1750 \mathrm{rpm}$ and with a constant injection timing of $28^{\circ}$ before top dead center (bTDC). At first the engine was run with diesel only and then subsequently run with NG and biogases in dual fuel mode. Two modes of steady state operation were chosen for diesel only operation: low load $(\sim 3 \mathrm{Nm})$ and high load $(\sim 28 \mathrm{Nm})$ which were about $8 \%$ and $75 \%$ of the rated output of the engine respectively at this engine speed. Under dual fuel operation, the amount of pilot diesel was kept constant at that corresponding to $3 \mathrm{Nm}$ load and the output of the engine was increased to $28 \mathrm{Nm}$ by increasing the gas flow rate to the engine. The operating fuel-air equivalence ratios were calculated as $0.23,0.61,0.67,0.65,0.69$ and 0.70 for diesel (low), diesel (high), dieselNG, diesel-BG1, diesel-BG2 and diesel-BG3 fueling respectively. The diesel replacement rate (on mass basis) was calculated as about 62 percent during dual fuel operations using the formula presented in [21],

$\mathrm{DR}(\%)=\frac{(\mathrm{DCR})_{\mathrm{d}}-(\mathrm{DCR})_{\mathrm{df}}}{(\mathrm{DCR})_{\mathrm{d}}} \times 100$

where $(\mathrm{DCR})_{\mathrm{d}}$ is the diesel consumption $(\mathrm{kg} / \mathrm{hr})$ under diesel operation and $(\mathrm{DCR})_{\mathrm{df}}$ is the diesel consumption rate under dual fuel operation $(0.6 \mathrm{~kg} / \mathrm{hr}$ is maintained in this study).

\section{Experimental heat release analysis}

Heat release analyses include calculations which yield how much heat would have to be added to the 
cylinder contents in order to produce the observed variations in cylinder pressure [27]. Using the average measured cylinder pressure diagram and the TDC signal, ignition delay, combustion duration and the rate of heat release were estimated. The high speed data obtained for cylinder pressure measurements were processed by using a computer program CoBRA (Combustion Burn Rate Analysis) developed and modified by the Internal Combustion Engine Group at University of Oxford $[28,29]$. It is usually assumed that the products and reactants are fully mixed. Considering the space trapped in the cylinder when the valves are closed as a control volume, and then the first law of thermodynamics can be applied for the closed system as:

$$
\delta Q_{\mathrm{hr}}=\mathrm{d} U+\delta W+\delta Q_{\mathrm{ht}}
$$

where, $Q_{\mathrm{hr}}=$ the heat release by combustion; $\delta W=$ mechanical work done by the system and $\delta Q_{\mathrm{ht}}=$ heat lost to combustion chamber walls.

Considering the cylinder content as an ideal gas (such that $c_{\mathrm{p}} / c_{\mathrm{v}}=\gamma$ and $c_{\mathrm{p}^{-}} c_{\mathrm{v}}=R$ ), the Eq. (2) finally can be modified as

$$
\frac{\mathrm{d} Q_{\mathrm{n}}}{\mathrm{d} \theta}=\frac{\mathrm{d} Q_{\mathrm{hr}}}{\mathrm{d} \theta}-\frac{\mathrm{d} Q_{\mathrm{ht}}}{\mathrm{d} \theta}=\frac{\gamma}{\gamma-1} p \frac{\mathrm{d} V}{\mathrm{~d} \theta}+\frac{1}{\gamma-1} V \frac{\mathrm{d} p}{\mathrm{~d} \theta}
$$

where $\mathrm{d} Q_{\mathrm{n}} / \mathrm{d} \theta$ is the net heat release rate which is the difference between the apparent gross heat release rate $\mathrm{dQ}_{\mathrm{hr}} / \mathrm{d} \theta$ and the heat lost to the walls $\mathrm{d} Q_{\mathrm{h} t} / \mathrm{d} \theta$. This equals the rate at which work is done on the piston plus the rate of change of sensible internal energy of the cylinder contents. The cumulative net heat release $Q_{\mathrm{n}}$ can be obtained by the integration of Eq. (3) $[29,30]$. The assumptions made for the analysis are similar as reported in [31].

It should be noted that the calculation of the net heat release rate is only valid between the inlet valve closure (IVC) and the exhaust valve opening (EVO) as a constant mass is considered. The value of $\gamma$ ranges from 1.3 to 1.35 for diesel heat release analysis. However, the appropriate values of $\gamma$ for the most accurate heat release analysis are not well defined [30]. In the heat release analysis, the specific heat ratio, $\gamma$, being a function of temperature has an influence on the magnitude of $Q_{\mathrm{n}}$ and $\mathrm{d} Q_{\mathrm{n}} / \mathrm{d} \theta$. It was understood that the presence of diluent $\mathrm{CO}_{2}$ in gaseous fuel would cause a lower value of $\gamma$. 
However, the authors in [29] suggested that the effect of changes in $\gamma$, within a typical range, on the phasing of $Q_{\mathrm{n}}$ and $\mathrm{d} Q_{\mathrm{n}} / \mathrm{d} \theta$ is negligible. Hence a constant value (1.35) of specific heat ratio, $\gamma$, was used for all the cases in using CoBRA for heat release analysis in this study.

\section{Results and discussions}

\subsection{Cylinder Pressure}

The pressure traces were the average of about 55 combustion cycles for each case. As expected, at diesel low load a lower maximum cylinder pressure was obtained than for diesel high load. Figure 1a shows the in-cylinder pressure characteristics of the test engine for all types of engine fueling: low load $(\sim 3 \mathrm{Nm})$ and high load $(\sim 28 \mathrm{Nm})$, at $1750 \mathrm{rpm}$ engine speed. At low load the engine operated at a lean condition ( $\phi \sim 0.23$ compared to $\phi \sim 0.61$ at high load), which affected the pre-ignition reaction activities of the fuel-air mixture and the corresponding effective flammability limit which resulted in delayed and lowered combustion pressure. Increasing fuel injection improved the situation and the maximum cylinder pressure rise was approximately proportional to the rate of diesel injection into the combustion chamber.

From Fig.1a, a similar peak cylinder pressure was observed for the diesel (high) and dual fueling irrespective of gaseous fuel nature in the present study. However, the peaks for dual fueling appeared later in the cycle as compared to diesel fueling which was mainly the result of increased ignition delay. During dual fueling, the operating total fuel-air equivalence ratio, $\phi$ was always found to be higher than that of diesel fueling which caused rapid energy release and greater rate of pressure rise [32]. Figure $1 \mathrm{~b}$ shows the pressure traces for dual fueling only, to compare results between NG and biogas fueling. It was observed that addition of $\mathrm{CO}_{2}$ in gaseous fuel did not significantly affect the maximum cylinder pressure, but the ignition and the peak of the cylinder pressures occurred slightly later in the cycle for biogas3 compared to NG fueling. Karim and Weirzba [20] also observed that the deterioration in maximum cylinder pressure and lower brake power output due to the presence of $\mathrm{CO}_{2}$ in methane improved significantly at higher total equivalence ratios for biogas fueling. 


\subsection{Heat Release Rate}

Net heat release rates (NHRR) for different engine fueling were calculated using the computer program CoBRA (as mentioned before) based on the measured in-cylinder pressure versus crank angle data. The net heat release is the difference between the gross heat release due to combustion and the heat transfer to the walls, crevice effects, the effect of fuel evaporation and heat up [30]. NHRR are presented for diesel and dual fueling in Fig.2. About 43\% higher maximum NHRR was calculated for diesel high load compared to light low condition (not shown here) and also a longer combustion was noticed for diesel high load than diesel low load operation. In the case of dual fueling a rapid and higher maximum energy release rate occurred compared to diesel (high) fueling due to the combined effect of the combustion of pilot as well as the gaseous fuel in the immediate vicinity of the ignition and combustion centers of the pilot. The energy release in the third phase of the combustion (diffusion), which was within the overall lean mixture, was found to be small. About $27 \%$ and $30 \%$ higher maximum NHHR were obtained for NG and biogas fueling respectively compared to diesel fueling. Among all the fueling conditions, biogas 3 had the highest maximum NHRR. Much energy was found to be released immediately following the commencement of the auto-ignition of the pilot. A similar observation was reported by Karim in [13]. This was due to the increase in the concentration of gaseous fuel in air and the corresponding overall equivalence ratio which modifies and extends significantly the flammability zone around the pilot fuel [32]. On a mass fraction basis

$\left(\frac{\dot{\mathrm{m}}_{\text {gas }}}{\dot{\mathrm{m}}_{\text {gas }}+\dot{\mathrm{m}}_{\text {diesel }}}\right)$, the value increased from 0.62 (for NG) to 0.67 for biogas $1,0.77$ for biogas 2 and to 0.8 for biogas 3 . This higher premixed combustion phase for methane fueling compared to diesel fueling was also reported by Patterson et al. [17]. The other authors, e.g. [33] observed that the maximum rate of heat release during the premixed phase of gaseous fuel combustion increased linearly while the diffusion combustion heat release rate decreased (due to decrease in diesel quantity that had to burn during diffusion combustion) proportionately with the increase in diesel substitutions in a dual fuel engine.

Cumulative heat release (CHR) is plotted in Fig. 3 for all types of engine fueling conditions. Although 
the NHRR was higher in the case of dual fueling compared to diesel (high) fueling, the cumulative heat release was found to be higher in the latter case. This indicated a longer duration of combustion in the case of diesel (high) fueling compared to dual fueling. The slope of the cumulative heat release rate curves also indicated that more rapid combustion occurs during dual fueling as indicated by higher NHRR.

\subsection{Ignition Delay and Duration of Combustion}

The ignition delay is the time interval between the start of injection and the start of combustion [30]. The start of combustion may be taken as the minimum point on the CHR curve (where the NHRR becomes positive, Fig. 2) and the maximum point on the CHR curve (where the NHRR becomes negative) may be considered as the end of combustion [29]. Ignition delay of the injected pilot fuel for dual fueling is different from that in an ordinary diesel engine. This is due to the presence of primary fuel mixed with air, which alters the properties of the charge, the oxygen concentration and the preignition reaction activities during compression [34]. The ignition delay period usually increases with an increase in the amount of gaseous fuel in the charge for most gaseous fuels under normal operating conditions [35].

Table 2 presents the calculated ignition delay and the combustion duration periods (based on CHR) for all fueling conditions. The ignition delay period was longer for diesel low load than for diesel high load as expected. In the case of dual fueling, ignition delay was found to be longer compared to diesel fueling. This can be attributed to several interacting effects including: reduced oxygen partial pressure due to air displacement by gaseous fuel; reduced temperature and pressure during the initiation of the ignition as methane has a higher heat capacity than air; pre-ignition reaction activities between methane and air may affect those between diesel and air; increased residuals concentration at higher loads [36]. Longer ignition delay periods for dual fueling with NG or methane are also reported by several authors including $[13,17,31,37]$. The ignition delay was affected further due to the presence of $\mathrm{CO}_{2}$ in gas as $\mathrm{CO}_{2}$ has a high specific heat capacity. However, the presence of $\mathrm{CO}_{2}$ in biogas did not affect the ignition delay much in this study. The reasons might be due to using a relatively high pilot quantity $(\sim 0.6 \mathrm{~kg} / \mathrm{hr})$ and the relatively high overall equivalence ratios. 
According to Table 2, the duration of combustion was shortened significantly for dual fueling compared to diesel fueling as a reduced amount of diesel was injected. These results thus complemented the results of rapid and high energy release rates for the kind of fueling. Liu and Karim [32] also found that the higher the diesel substitution by the gaseous fuel, the shorter the combustion duration during experimenting with dual fuel engine. This was the combined effects of higher premixed phase combustion rate and the reduced diffusion phase combustion period. It can also be observed from Table 2 that the increase of $\mathrm{CO}_{2}$ concentration in biogas does not affect much the duration of combustion. This can be attributed to the combined effects of high operating $\phi$ as well as high engine load which significantly increases the flame speed and the fuel-air mixture flammability limit.

\subsection{Brake Fuel Consumption}

For each test condition, the fuel consumption rate was recorded at least three times. Based on power output for each test condition, the brake specific fuel consumption (BSFC) was calculated. Figure 4a shows that the specific fuel consumption increased as biogas was introduced into the engine. This can be attributed to the reduced calorific values of biogas fuels with higher $\mathrm{CO}_{2}$ contents. However, in the case of NG fueling an insignificant effect was observed on fuel consumption rate when compared with diesel fueling. A more useful comparison between the fuels used in the study, was to examine the brake specific energy consumption (BSEC) results for each engine test. The error bars on individual measurements are equivalent to two standard deviations to show the variability in data recorded in different tests and on different days. When fuel consumptions are viewed on an energy basis as shown in Fig. 4b, BSEC results are not significantly different between diesel and dual fueling and between NG and biogas fueling. These results indicate that at sufficiently high operating loads, as used here, dual fueling has similar thermal efficiency to that for diesel fueling and the fuel gas quality has an insignificant impact on it. Similar observations are also reported for high loads on NG-diesel dual fueling $[31,37,38]$.

\section{5. $N O_{x}$ Emissions}


Figure 5 shows the results of $\mathrm{NO}_{\mathrm{x}}$ emissions for the engine while operated in diesel and dual fuel modes. Significantly higher $\mathrm{NO}_{\mathrm{x}}$ concentration was measured during diesel high load operation. According to Fig.5, the $\mathrm{NO}_{\mathrm{x}}$ concentration level at low load was almost $1 / 3^{\text {rd }}$ of the level for high load which was approximately similar to the ratio of the diesel consumption rates between the low and high loads. Thus the $\mathrm{NO}_{\mathrm{x}}$ emissions were approximately proportional to the mass of diesel injected.

In the case of dual fueling, the combustion and emissions characteristics are strongly dependent on the type, quality and the level of substitution of the gaseous fuel as mentioned previously. The gas substitution levels are particularly important at higher loads. This is because the premixed charge is subjected to increasing temperatures during compression and thus causes a substantial progress in the pre-ignition activity. This increased reaction activity increases the charge temperature, which tends to compensate for the temperature drop due to the addition of the gaseous fuel [17]. Thus, at a sufficiently high load with higher gas substitution, the combustion temperatures are not affected much compared to the diesel fueling, which may cause similar level of $\mathrm{NO}_{\mathrm{x}}$ emissions. This was the case in our experiments with dual fueling and when comparing between diesel and NG fueling under the same operating condition (28 $\mathrm{Nm}$ and $1750 \mathrm{rpm}$ ), where $\mathrm{NO}_{\mathrm{x}}$ emissions were found to be slightly lower or similar. However, from Fig.5, $\mathrm{NO}_{\mathrm{x}}$ emissions were found to be reduced significantly for biogas fueling compared to either diesel or diesel-NG fueling. $\mathrm{NO}_{\mathrm{x}}$ concentration was found to be decreased by about 13 to $37 \%$ during biogas fueling with increasing $\mathrm{CO}_{2}$ contents compared with diesel fueling. Therefore, it is clear that these notable differences in $\mathrm{NO}_{\mathrm{x}}$ concentrations were mainly due to the presence of $\mathrm{CO}_{2}$ in the gaseous fuel. $\mathrm{CO}_{2}$, being a diluent, and having a high molar specific heat capacity, lowered the level of the cycle temperatures significantly. In addition, increasing $\mathrm{CO}_{2}$ in biogas caused more gaseous fuel to escape the combustion process, which affected oxygen concentration followed by a decrease in overall cycle temperature. Hence, $\mathrm{NO}_{\mathrm{x}}$ formation was suppressed with the combined effects of these phenomena in the case of biogas fueling [19].

\subsection{UHC emissions}

Measured unburned hydrocarbon (UHC) emissions are presented in Fig. 6 for the different engine 
fueling conditions. A similar UHC concentration was found for diesel low and high load conditions. However, with the introduction of gaseous fuel, UHC emissions increased sharply by more than three times compared to baseline diesel fueling. Similar results were reported by Papagiannakis and Hountalas [31] for diesel-NG fueling at higher engine loads. With the introduction of gaseous fuels, turbulent flame propagation from the ignition regions of the pilot is normally suppressed due to the lower temperature and air-fuel ratio and it will not proceed until the concentration of the gaseous fuel reaches a minimum limiting value. Also it is observed that the ignition is normally more delayed for dual fueling compared to diesel fueling which has an approximately directly proportional relationship with the exhaust UHC concentration for a naturally aspirated DI engine [30]. In addition to these mechanisms, there are contributions from crevice volumes into which gas-air mixture is forced during compression, and remains partially unburned after completion of the expansion process. Valve overlapping between the intake and exhaust to facilitate scavenging can also cause an increase in $\mathrm{HC}$ emissions for dual fueling as it blows unburned gas-air mixture out of the cylinder [39]. For biogas fueling, a mild increase in $\mathrm{HC}$ emissions was observed (Fig. 6) with the increase of $\mathrm{CO}_{2}$ content in fuel. This can be attributed to the effects of lowering combustion temperature and oxygen concentration in the mixture which may narrow the effective flammability limits.

\subsection{PM Mass Emissions}

\subsubsection{Gravimetric method}

PM total mass emissions measured by the gravimetric method are presented in brake-specific mass unit $(\mathrm{g} / \mathrm{kWh})$ in Fig. 7 for diesel and dual fueling conditions. Under diesel low load condition, the PM mass emissions per engine output power were found to be the highest among all other operating conditions. A similar observation was reported by Ogawa et al. [40] for the low load operations with different diesel test fuels. When compared between diesel and dual fueling, a significant reduction in PM mass emissions was obtained in the latter case (Fig. 7). Specific PM mass emissions were reduced by about 70 percent for NG, biogas- 1 and about 75 percent for biogas- 2 and biogas- 3 dual fueling compared to diesel high load operation. Quantitatively similar results were reported for diesel-NG dual fuel operation in $[41,42]$. 
It can be speculated that the formation of the majority of PM was caused by the quantity of diesel fuel injected which was minimized in the case of dual fuel operations as soot forms in fuel rich zones at the elevated temperatures from liquid hydrocarbon fuel droplets. On the other hand, PM oxidation processes, being a function of temperature, in dual fuel combustion are almost similar to diesel high load combustion as the combustion temperature remained unaffected much (combustion temperatures can be approximated to be proportional to the exhaust temperatures which ranged from $450^{\circ} \mathrm{C}$ to $467^{\circ} \mathrm{C}$ for dual fueling and from $470^{\circ} \mathrm{C}$ to $485^{\circ} \mathrm{C}$ for diesel (high) fueling). It is generally believed that the more carbon a fuel molecule contains, the more likely the production of soot by the fuel during combustion [43]. Moreover, the chemical structures such as aromatics, $\mathrm{C}=\mathrm{C}$ and cyclic molecules, which are regarded to have increased PM producing tendency, are absent in gaseous fuels such as NG or biogas $[43,44]$. The reduction in PM emissions in this study were attributed to (a) a direct consequence of flame temperature reduction (resulting a lower PM nucleation rate) and the lowered concentration (or mass fraction) of acetylene, (b) increased oxidation of soot nuclei/precursors in the soot forming region by the enhanced concentrations of $\mathrm{O}$ and $\mathrm{OH}$ around the flame (resulting in the high oxidation attack) that was produced from the $\mathrm{CO}_{2}$ reaction mechanism $[45,46]$. From the Fig.7 it is also observed that the more $\mathrm{CO}_{2}$ in biogas, the more reduction in PM mass emissions. The presence of higher $\mathrm{CO}_{2}$ concentration in the fuel causes a decrease in overall cycle temperature which might have an impact on oxidation processes. Hence, the resultant PM emissions would be the balance between these two phenomena. Ignition delay has a role to reduce PM formation in diesel combustion. The longer the ignition delays the more homogeneity in the fuel-air mixture and the fewer tendencies to PM formation [44]. In addition to the increased ignition delays, decreased combustion duration was also observed for dual fueling. Therefore, most of the combustion occurred at higher temperatures which could facilitate PM oxidation in this case whereas in diesel fueling the PM that was produced later in the expansion stroke would not have enough time and high enough temperatures to be oxidized.

\subsubsection{Light scattering photometer (LSP) method}


Figure 8 presents the comparative results of PM mass emissions obtained by LSP and gravimetric methods. The emission values are averaged and expressed as PM mass per unit volume of diluted sample passed through the collecting filters. It can be observed from Fig. 8 that LSP shows a similar trend of PM emissions for different engine fueling conditions. PM mass emissions $\left(\mathrm{mg} / \mathrm{m}^{3}\right)$ were found to be reduced by about 84 percent for dual fueling compared to diesel fueling at high load. However, agreement of the comparative results between diesel low and high load was not good. LSP underestimated for low load, and overestimated for high load condition during diesel fueling when compared with the gravimetric method. Similar observations were previously reported in [47]. In this present study, LSP was not calibrated for the specific engine operation. The zero check was done frequently and the repeatability for a specific engine operation was good.

\section{Conclusions}

In the present work an experimental investigation was conducted to examine the effect of dual fuel combustion on the performance and pollutant emissions of a DI diesel engine operated on alternative gaseous fuels such as NG and biogas. The engine operation was found to stable and smoother in dual fuel mode at the engine operating conditions considered in this study. The following conclusions may be drawn from the results of the present study:

- The highest BSFC was obtained for diesel low load operation. When the engine operating condition changed from diesel (high) to diesel-NG fueling, the effect on BSFC was found to be insignificant. However, with the introduction of biogases, the BSFC increased compared to diesel fueling as the fuel calorific value decreased. The increase in BSFC was found to be proportional to the amount of $\mathrm{CO}_{2}$ present in the simulated biogases. When fuel consumptions are converted to an energy basis, BSEC, results are not significantly different between diesel and dual fueling and between NG and simulated biogas fueling. Hence it can be concluded that at sufficiently high operating loads, as used in this work, dual fueling has similar thermal efficiency to that for diesel fueling and the fuel gas quality has no impact on this efficiency.

- Maximum cylinder pressure was found to be affected due to the variation in engine load. 
However, a similar maximum cylinder pressure was noted for diesel (high) and dual fueling irrespective of fuel gas quality at this high load. In the case of dual fueling, the maximum cylinder pressure was also found to occur later in the cycle implying a longer ignition delay when compared to diesel (high) fueling. A longer ignition delay period was also calculated for diesel low load and dual fuel conditions compared to that of diesel high load. The presence of higher $\mathrm{CO}_{2}$ in the gaseous fuel also caused a longer ignition delay.

- In the case of dual fueling, a rapid and higher maximum energy release rate occurred compared to diesel (high) fueling. About $27 \%$ and $30 \%$ higher maximum NHRR were obtained for NG and biogas fueling respectively compared to diesel fueling. However, the cumulative heat release was found to be lower (by about 30\%) for dual fueling compared to diesel (high) fueling. These results indicate that dual fuel combustion is characterized by a rapid and higher energy release rate, with relatively shorter combustion duration, as compared to diesel fuel combustion under the same operating conditions. About $22 \%$ shorter combustion duration (on an average) was calculated for dual fueling compared to diesel (high) fueling.

- NOx emissions for NG-diesel dual fueling were found to be similar to those for diesel high load condition. However, biogas fueling significantly lowered the NOx emissions (maximum by $37 \%$ compared to diesel fueling). NOx reduction was observed to be proportional to the $\mathrm{CO}_{2}$ concentration in biogas.

- With the introduction of gaseous fuel, UHC emissions increased sharply by more than three times compared to baseline diesel fueling. When compared between NG and biogas fueling, a mild increase (about 6\% increment for biogas3 fueling) in UHC emissions was observed with the increase of $\mathrm{CO}_{2}$ content in the fuel. It is thus indicated that up to $41 \% \mathrm{CO}_{2}$ in biogas is tolerable in terms of UHC emissions when compared with NG fueling (at high load).

- PM mass emissions were reduced substantially in the case of dual fueling irrespective of its quality. About $70 \%$ reductions in PM emissions were obtained in this study. Similar results are observed for NG and biogas fueling.

- Online PM measurements using light scattering photometer (LSP) showed a similar trend of 
results to those obtained by the gravimetric method. However, quantitatively the LSP measured a lower value for diesel (low) or dual fueling conditions and a higher value for diesel (high) condition when compared with the corresponding gravimetric results.

\section{Acknowledgement}

The authors gratefully acknowledge the financial support from VLIR-UOS grant SRS PhD+ Scholarship of Belgium for this publication.

\section{References}

[1] Yoon S. H. and Lee C. S. Experimental investigation on the combustion and exhaust emission characteristics of biogas-biodiesel dual-fuel combustion in a CI engine. Fuel Process Technol. 2011;92:992-1000.

[2] Müller J.-O., Su D.S., Jentoft R.E., Wild U. and Schlögl R. Diesel engine exhaust emission: Oxidative behavior and microstructure of black smoke soot particulate. Environ Sci Technol. 2006;40:1231-1236.

[3] Zhu J., Aikawa B. and Pigeon R. Measurement of fine particles in diesel emissions using a realtime aerosol monitor. J Air Waste Manage Assoc. 2005;55:978-983.

[4] Zhu J., Lee K. O., Yozgatligil A., and Choi M. Y. Effects of engine operating conditions on morphology, microstructure, and fractal geometry of light-duty diesel engine particulates. Proc Combust Inst. 2005;30:2781-2789.

[5] El-Zein, A., Nuwayhid, I., El-Fadel, M. and Mroueh, S. Did a ban on diesel-fuel reduce emergency respiratory admissions for children? Sci Tot Environ. 2007;384(1-3):134-140.

[6] McClellan R. O., Hesterberg T. W. and Wall J. C. Evaluation of carcinogenic hazard of diesel engine exhaust needs to consider revolutionary changes in diesel technology. Regul Toxicol Pharmacol. 2012;63:225-258.

[7] Vouitsis E., Ntziachristos L. and Samaras Z. Particulate matter mass measurements for low emitting diesel powered vehicles: What's next? Progress Energy Combust Sci. 2003;29(6):635672.

[8] Nabi N. M. and Hustad E. Influence of oxygenates on fine particle and regulated emissions from a diesel engine. Fuel 2012;93:181-188.

[9] Rahmouni, C., Tazerout, M., and Le Corre, O. A method to determine biogas composition for combustion control. SAE Technical Paper 2002-01-1708; 2002.

[10] Mustafi Nirendra N., Raine Robert R. and James Bryony. Characterization of exhaust particulates from a dual fuel engine by TGA, XPS and Raman techniques. Aerosol Sci Technol. 2010;44(11):954-963.

[11] Huang J, Crookes RJ. Assessment of simulated biogas as a fuel for the spark ignition engine. Fuel 1998;77(15):1793-801.

[12] Karim G. A. A review of combustion processes in the dual fuel engine - the gas diesel engine. Prog Energy Combust Sci. 1980;6:277-285.

[13] Karim G.A. Combustion in gas fueled compression ignition engines of the dual fuel type. ASME J Eng Gas Turbines Power 2003;125:827-836.

[14] Pirouzpanah V, Sarai RK. Reduction of emissions in an automobile direct injection diesel engine dual-fuelled with natural gas by using variable exhaust gas recirculation. Proc Inst Mech Eng, Part D, J Automob Eng. 2003;217:719-724.

[15] Singh S., Krishnan S.R., Srinivasan K.K., Midkiff K.C., and Bell S.R. Effect of pilot injection timing, pilot quantity and intake charge conditions on performance and emissions for an advanced low-pilot-ignited natural gas engine. Int J of Eng Res. 2004;5:329-348.

[16] Selim M.Y.E. Effect of engine parameters and gaseous fuel type on the cyclic variability of dual fuel engines. Fuel 2005;84:961-971.

[17] Patterson J., Clarke A. and Chen R. Experimental study of the performance and emissions 
characteristics of a small diesel Genset operating in dual-fuel mode with three different primary fuels. SAE Paper no. 2006-01-0050; 2006.

[18] Papagiannakis R.G., Rakopoulos C.D., Hountalas D.T., Rakopoulos D.C. Emission characteristics of high speed, dual fuel, compression ignition engine operating in a wide range of natural gas/diesel fuel proportions. Fuel 2010;89:1397-1406.

[19] Karim G.A. and Amoozegar N. Examination of the performance of a dual fuel diesel engine with particular reference to the presence of some inert diluents in the engine intake charge. SAE Paper no. 821222; 1982.

[20] Karim G. A. and Wierzba I. Methane-carbon dioxide mixtures as a fuel. SAE Paper no. 921557; 1992.

[21] Mustafi Nirendra N. and Raine Robert R. A study of the emissions of a dual fuel engine operating with alternative gaseous fuels. SAE Technical Paper no. 2008-01-1394; 2008.

[22] Bedoya I. D., Arrieta A. A. and Cadavid F. J. Effects of mixing system and pilot fuel quality on diesel-biogas dual fuel engine performance. Biores Technol. 2009;100:6624-6629.

[23] Yoon S. H. and Lee C. S. Experimental investigation on the combustion and exhaust emission characteristics of biogas-biodiesel dual-fuel combustion in a CI engine. Fuel Process Technol. 2011;92:992-1000.

[24] Luijten C.C.M. and Kerkhof E. Jatropha oil and biogas in a dual fuel CI engine for rural electrification. Energy Convers Manage. 2011;52:1426-1438.

[25] Bedoya I. D., Saxena S., Cadavid F. J., Dibble R. W. and Wissink M. Experimental study of biogas combustion in an HCCI engine for power generation with high indicated efficiency and ultra-low NOx emissions. Energy Convers Manage. 2012;53:154-162.

[26] Zhu J., Aikawa B., and Pigeon R. Measurement of fine particles in diesel emissions using a realtime aerosol monitor, J Air Waste Manage Assoc. 2005;55:978-983.

[27] Stone R. Introduction to internal combustion engines. $3^{\text {rd }}$ ed. New York: Macmillan; 1999.

[28] Ball J., Raine R. and Stone R. Combustion analysis and cycle-by-cycle variations in spark ignition engine combustion. Parts 1 and 2. Proc Inst Mech Eng, Part D, J Automob Eng. 1998;212(D5):381-398 and 212(D6):507-523.

[29] Ma H., Kar K., Stone R., Raine R. and Thorwarth H. Analysis of combustion in a small homogeneous charge compression assisted ignition engine. Int J of Eng Res. 2006;7(3):237-253.

[30] Heywood J. B. Internal Combustion Engine Fundamentals. New York:McGraw - Hill; 1988.

[31] Papagiannakis R. G. and Hountalas D. T. Combustion and exhaust emission characteristics of a dual fuel compression ignition engine operated with pilot Diesel fuel and natural gas, Energy Convers Manage. 2004;45(18-19):2971-2987.

[32] Liu Z., Karim G.A. Simulation of combustion processes in gas-fuelled diesel engines. Proc Inst Mech Eng, Part A: J Power and Energy 1997;211(2):159-169.

[33] Bilcan A., Corre O. L. and Delebarre A. Thermal efficiency and environmental performances of a biogas-diesel stationary engine, Environ Technol. 2003;24:1165-1173.

[34] Prakash G. and Ramesh A. and Shaik A.B. An approach for estimation of ignition delay in a dual fuel engine. SAE Technical Paper No. 1999-01-0232; 1999.

[35] Poonia M.P., Ramesh A. and Gaur R.R. (1998). Effect of intake air temperature and pilot fuel quantity on the combustion characteristics of a LPG diesel dual fuel engine. SAE Paper 982455.

[36] Raine R.R. A performance model of the dual fuel (diesel/natural gas) engine. SAE Paper no. 900387; 1990.

[37] Galal M.G., Abdel Aal M.M., and El Kady M.A. A comparative study between diesel and dualfuel engines: Performance and emissions. Combust Sci Technol. 2002;174(11-12):241-256.

[38] Wong W.Y., Midkiff K.C., and Bell S.R. Performance and emissions of a natural gas dualfueled, indirect injected diesel engine. SAE Paper no. 911766; 1991.

[39] Weaver C.S. and Turner S.H. Dual fuel natural gas/diesel engines: technology, performance, and emissions. SAE Paper No. 940548; 1994.

[40] Ogawa T., Nakakita K., Yamamoto M., Okada M. and Fujimoto Y. Fuel effects on particulate emissions from D.I. engine - relationship among diesel fuel, exhaust gas and particulates. SAE Paper no. 971605; 1997.

[41] Boisvert J., Gettel L.E. and Perry G.C. Particulate emissions for a dual-fuel Caterpillar 3208 engine, ASME Paper 88-ICE-18, pp. 277-285; 1988. 
[42] Zbaraza D. Natural gas use for on-sea transport. Diploma thesis, University of Science and Technology Cracow, Poland; 2004.

[43] Tree D.R. and Svensson K.I. Soot processes in compression ignition engines. Progress Energy Combust Sci. 2007;33:272-309.

[44] Smith O.I. Fundamentals of soot formation in flames with application to diesel engine particulate emissions. Progress Energy and Combust Sci. 1981;7:275-291.

[45] Liu F., Guo H., Smallwood G.J., and Gulder O.L. The chemical effects of carbon dioxide as an additive in an ethylene diffusion flame: implications for soot and NOx formation. Combust Flame 2001;125:778-787.

[46] Zhao H., Hu J., Ladommatos N. In-cylinder studies of the effects of CO2 in exhaust gas recirculation on diesel combustion and emissions. Proc Inst Mech Eng, Part D, J Automob Eng. 2000;214(4):405-419.

[47] Cheung S.K., Elder S.T. and Raine R.R. Diesel particulate measurements with a light scattering photometer. SAE Paper no. 2000-01-1136; 2000. 


\section{$\underline{\text { Tables }}$}

Table 1. Engine specifications

\begin{tabular}{ll}
\hline Engine type & Single cylinder, DI, water cooled \\
Bore/Stroke & $87.3 / 110(\mathrm{~mm})$ \\
Swept volume & $659\left(\mathrm{~cm}^{3}\right)$ \\
Connecting rod length & $231.9(\mathrm{~mm})$ \\
Compression ratio & 16.5 \\
Injection timing by spill & $28^{\circ} \mathrm{bTDC}$ \\
Nozzle opening pressure & $197-217(\mathrm{bar})$ \\
Rated torque output (cont.) & $32.6($ at $1800 \mathrm{rpm}) \mathrm{Nm}$ \\
\hline
\end{tabular}


Table 2. Ignition delay and combustion duration periods for different engine fueling.

\begin{tabular}{lccc}
\hline Fueling & $\begin{array}{c}\text { Ignition } \\
\text { Delay } \\
\left({ }^{\circ} \mathrm{CA}\right)\end{array}$ & $\begin{array}{c}\mathrm{CO}_{2} \text { in } \\
\text { Biogas } \\
(\% \text { mole })\end{array}$ & $\begin{array}{c}\text { Duration of } \\
\text { Combustion } \\
(\mathrm{CHR} \text { based })\left({ }^{\circ} \mathrm{CA}\right)\end{array}$ \\
\hline Diesel (low) & 17 & --- & 44 \\
Diesel (High) & 15 & --- & 102 \\
Diesel-NG & 18 & --- & 81 \\
Diesel-BG1 & 19 & 20 & 82 \\
Diesel-BG3 & 19.5 & 41 & 78 \\
\hline
\end{tabular}




\section{FIGURES}

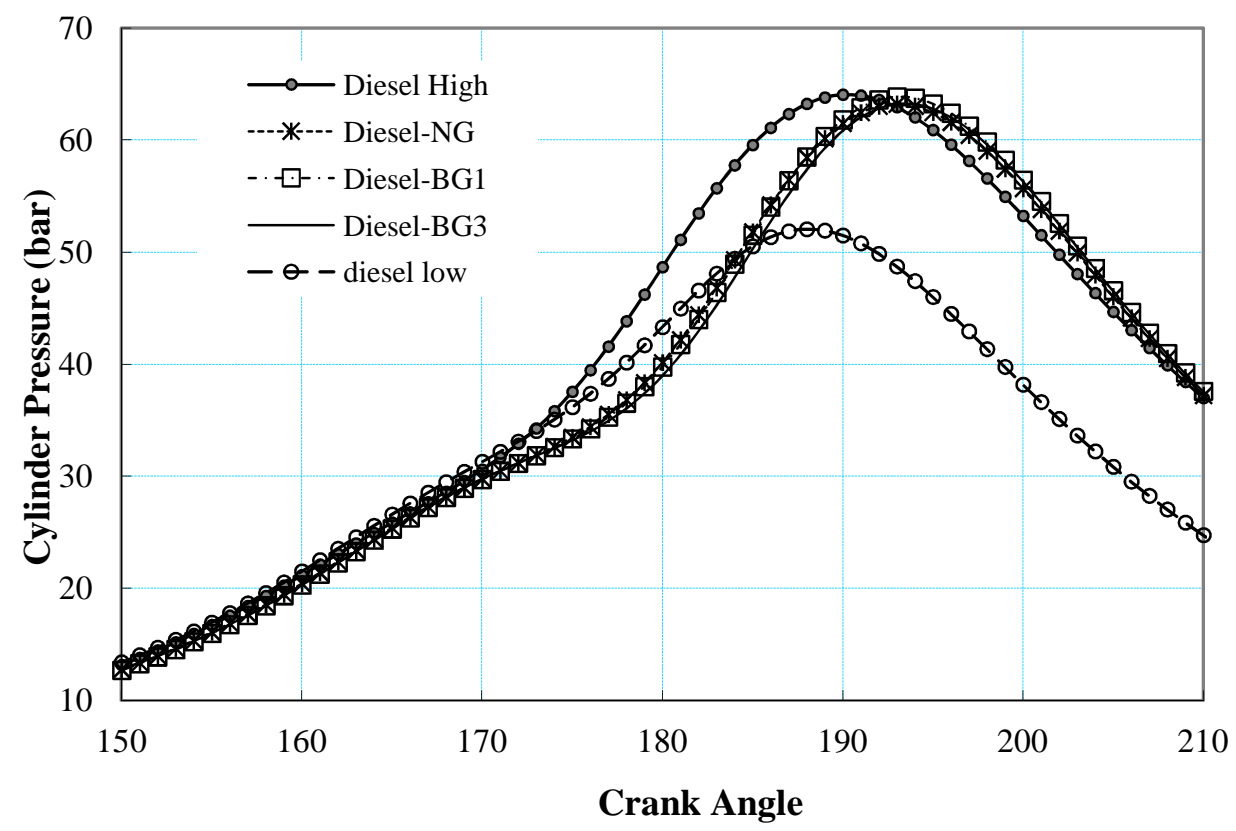

(a)

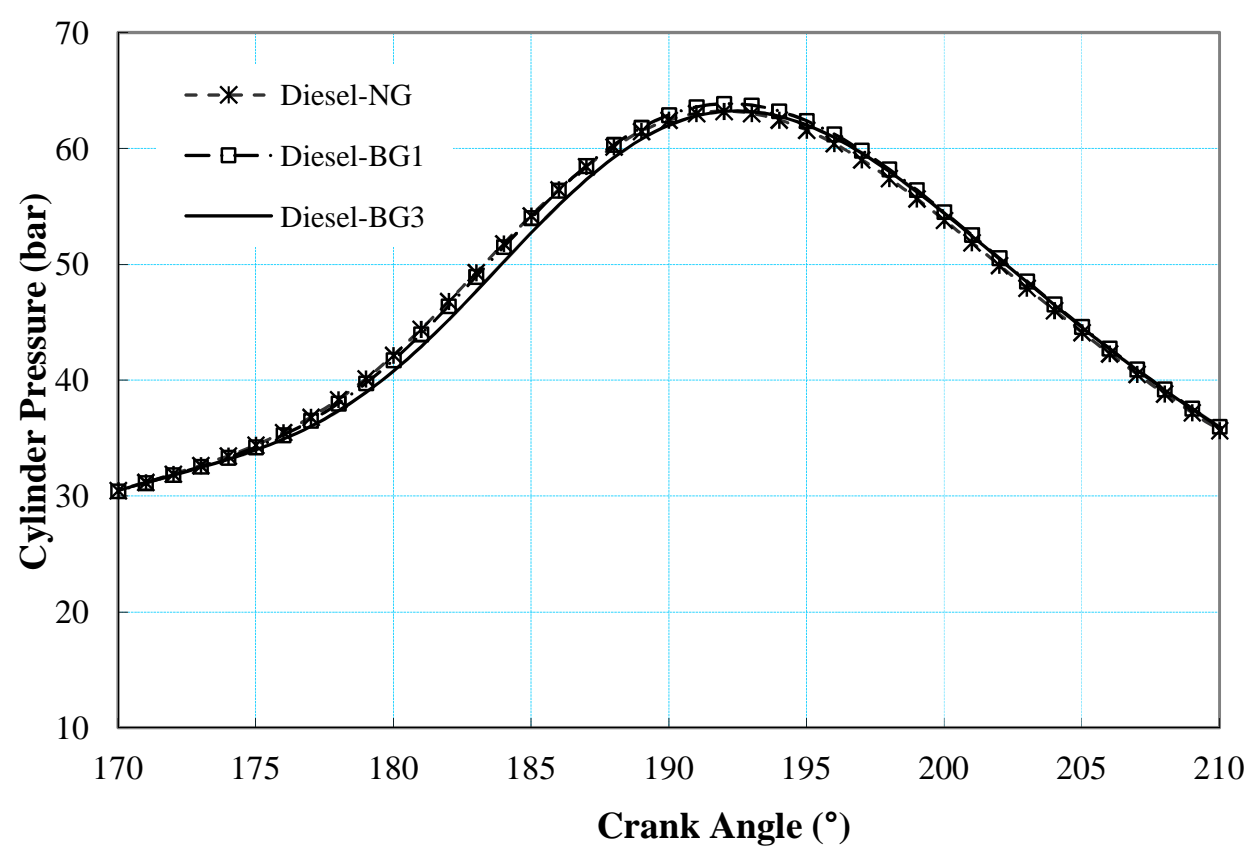

(b)

Figure 1. Cylinder pressure as a function of crank angle for (a) diesel and dual fueling and (b) dual fueling (28 Nm; at $1750 \mathrm{rpm}$ and $28^{\circ} \mathrm{bTDC}$ ). 


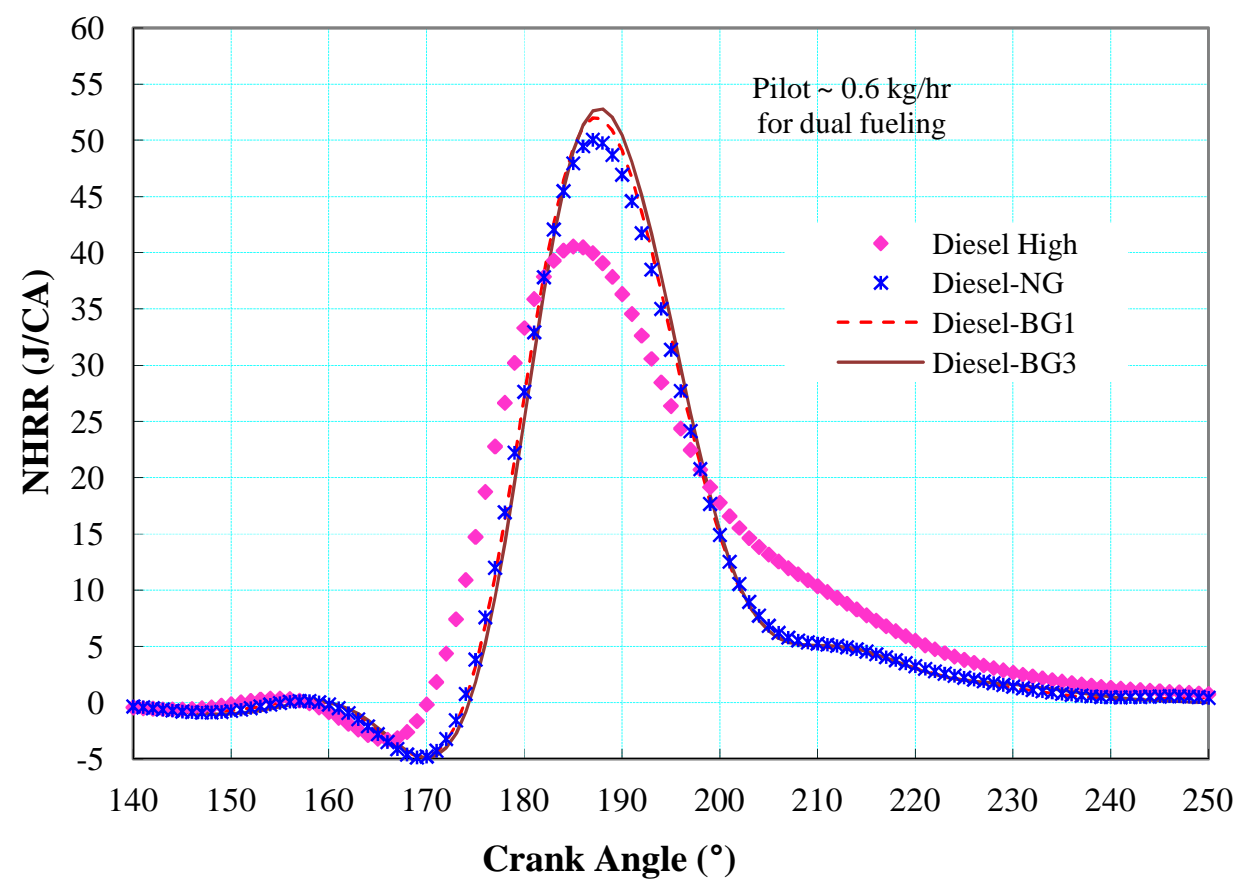

Figure 2. Net heat release rate as a function of crank angle for diesel (high) and dual fueling (28 $\mathrm{Nm}$; at $1750 \mathrm{rpm}$ and $28^{\circ} \mathrm{bTDC}$ ). 


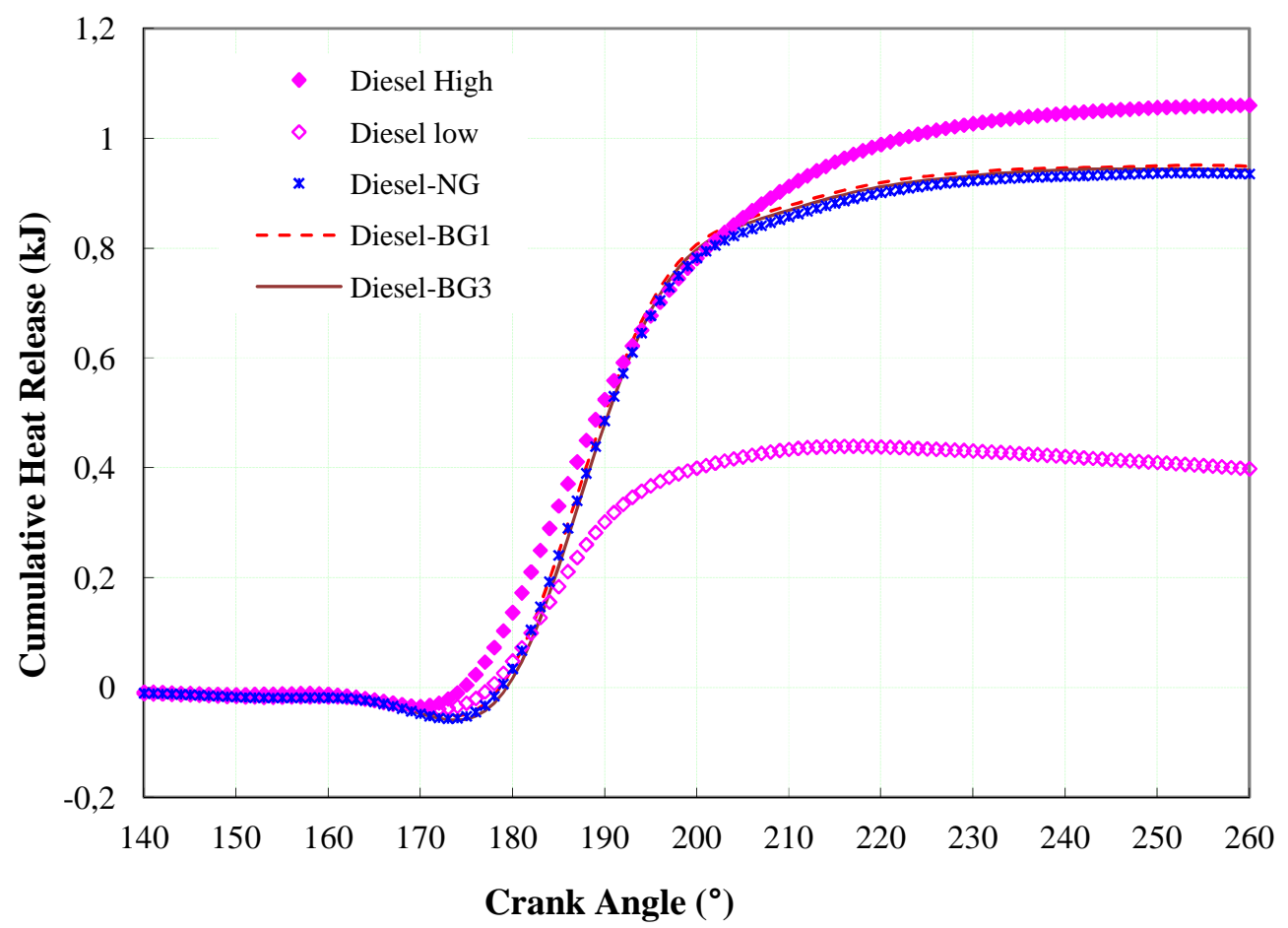

Figure 3. Cumulative heat release as a function of crank angle for diesel (high) and dual fueling (high: $28 \mathrm{Nm}$; at $1750 \mathrm{rpm}$ and $28^{\circ} \mathrm{bTDC}$ ). 


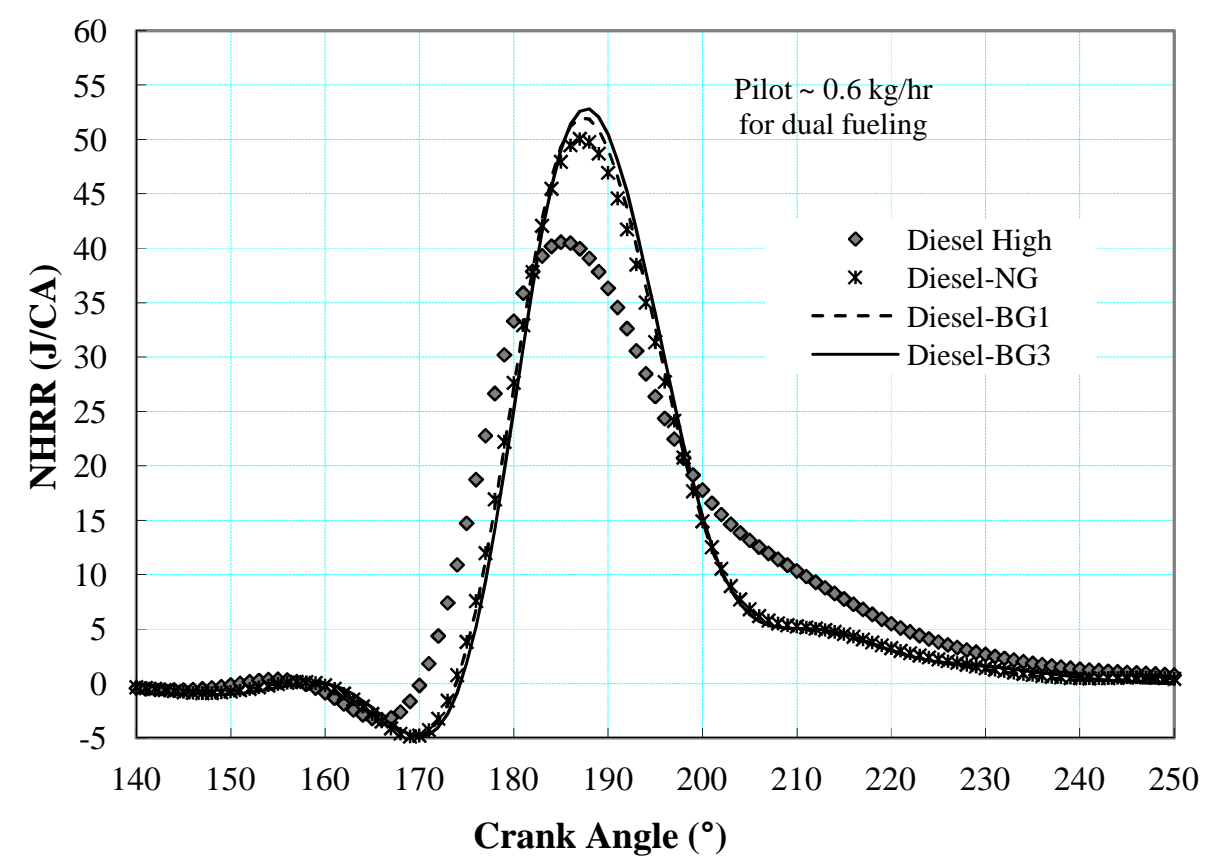

Figure 2. Net heat release rate as a function of crank angle for diesel (high) and dual fueling (28 $\mathrm{Nm}$; at $1750 \mathrm{rpm}$ and $28^{\circ} \mathrm{bTDC}$ ).

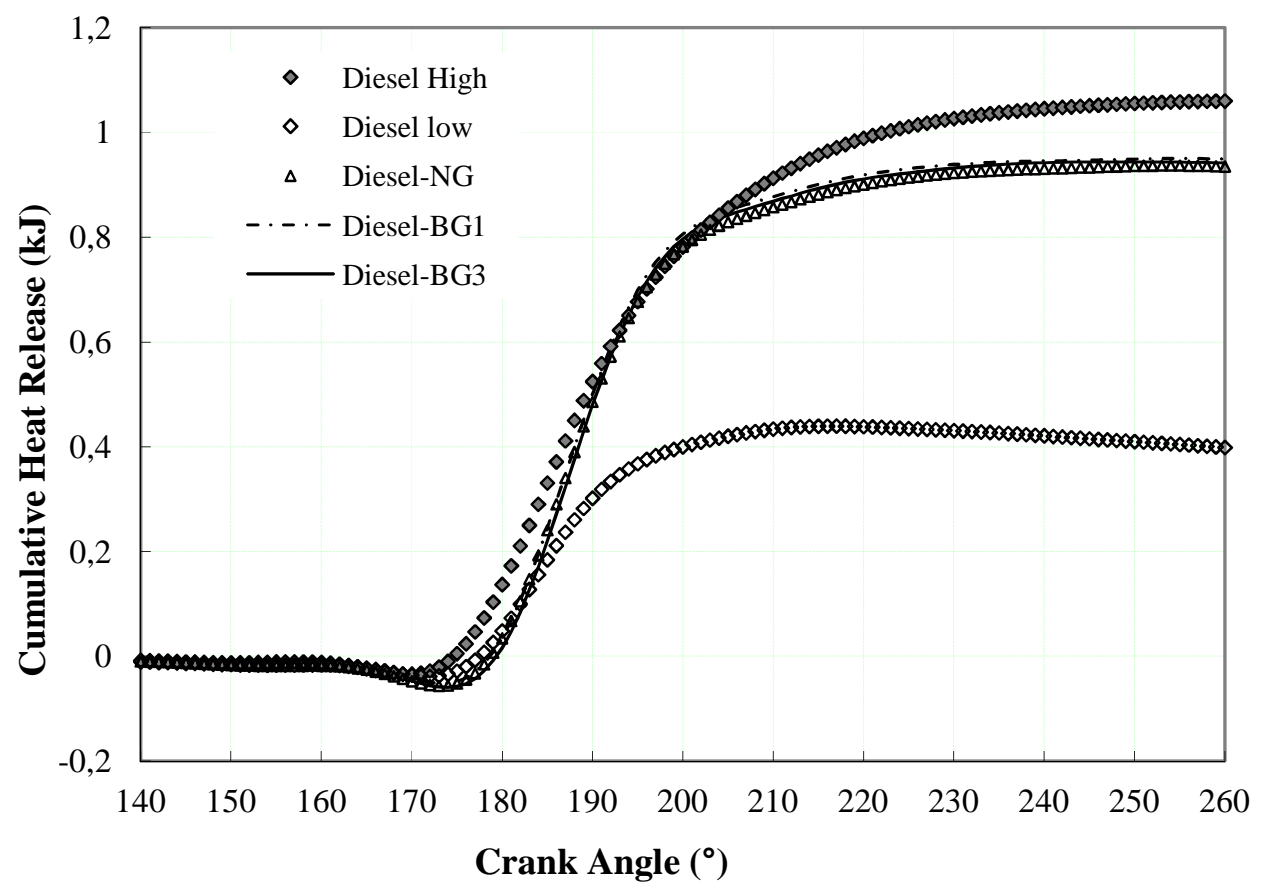

Figure 3. Cumulative heat release as a function of crank angle for diesel (high) and dual fueling (high: $28 \mathrm{Nm}$; at $1750 \mathrm{rpm}$ and $28^{\circ} \mathrm{bTDC}$ ). 


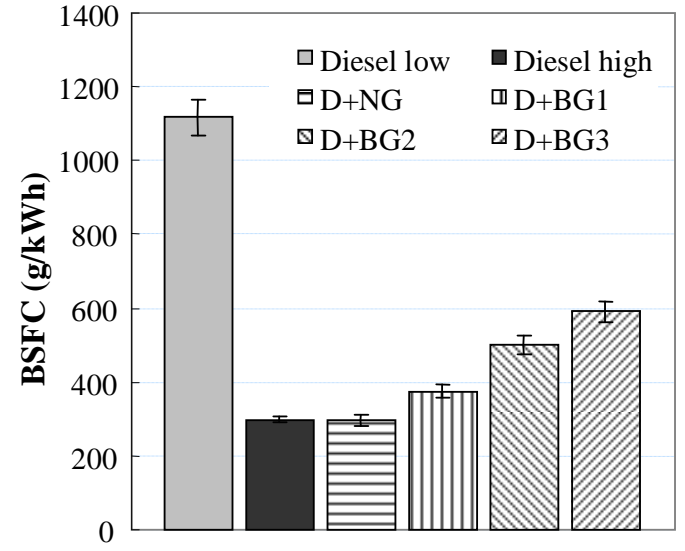

(a)

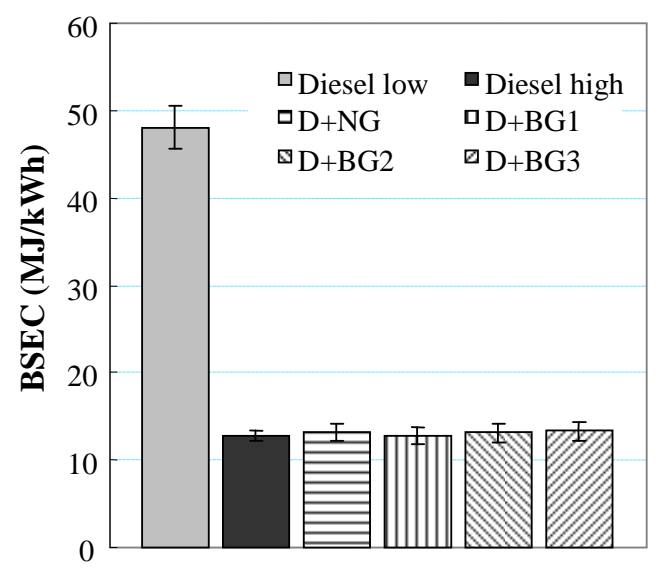

(b)

Figure 4. (a) Brake specific fuel consumption, and (b) brake specific energy consumption of the engine while operated with diesel and dual fuels (diesel low $\sim 3 \mathrm{Nm}$, diesel high and dual fueling $\sim 28 \mathrm{Nm}$, at $1750 \mathrm{rpm}$, and $28^{\circ} \mathrm{btdc}$ ). 


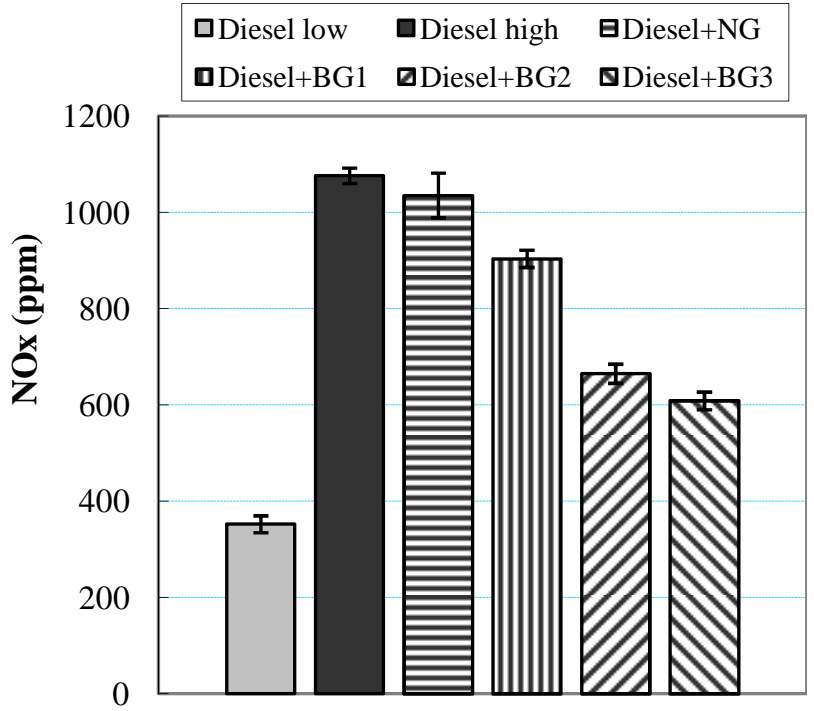

Figure 5. $\mathrm{NO}_{\mathrm{x}}$ concentrations in dry exhaust for diesel and dual fueling (engine speed $=1750$ $\mathrm{rpm}$; torque $=3 \mathrm{Nm}$ (diesel low load) and $28 \mathrm{Nm}$ for others; injection at $28^{\circ} \mathrm{btdc}$ ). 


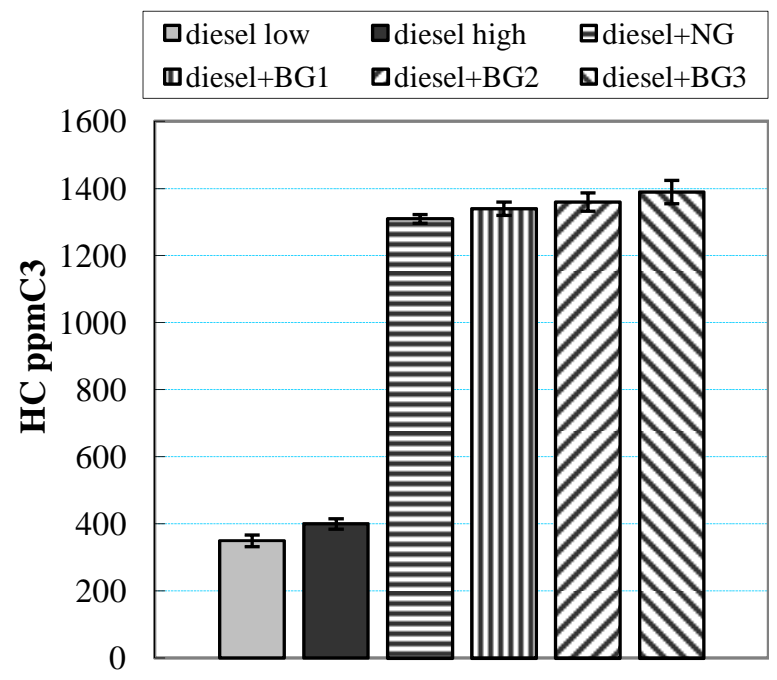

Figure 6. Unburned HC concentrations in dry exhaust for diesel and dual fueling (engine speed $=1750 \mathrm{rpm}$; torque $=3 \mathrm{Nm}$ (diesel low load) and $28 \mathrm{Nm}$ for others; injection at $28^{\circ} \mathrm{btdc}$ ). 


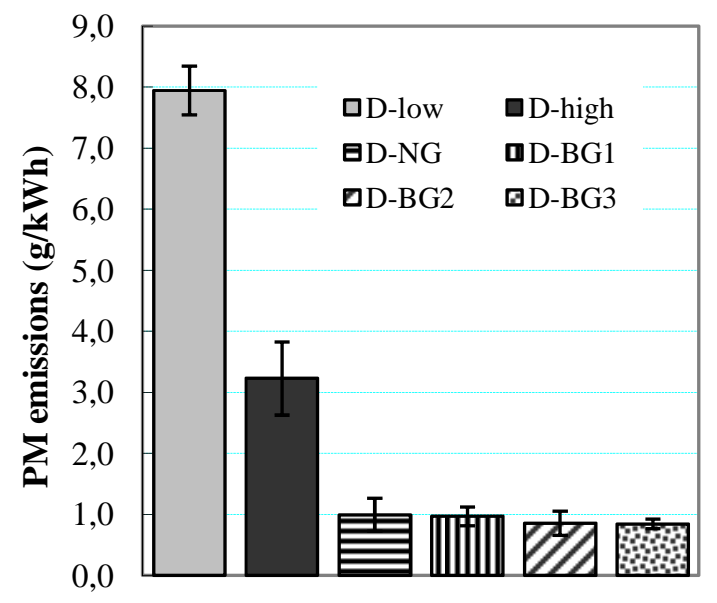

Figure 7. PM total mass emissions by gravimetric method for different engine fueling (diesel: 3 $\mathrm{Nm}$ and $28 \mathrm{Nm}$; dual fuel: $28 \mathrm{Nm} ; 1750 \mathrm{rpm} ; 28^{\circ} \mathrm{bTDC} ; 0.6 \mathrm{~kg} / \mathrm{hr}$ pilot for dual fueling). 


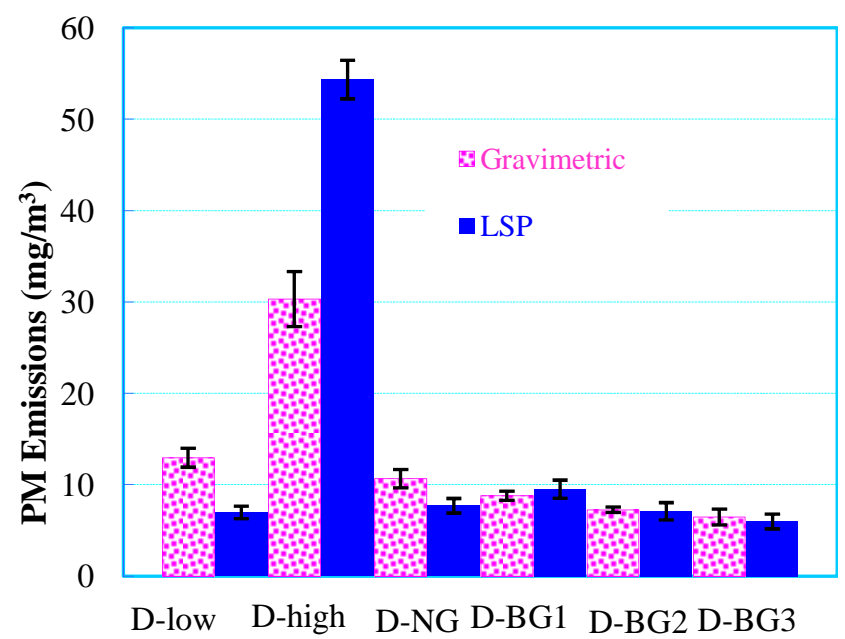

Figure 8. PM mass emissions by LSP method (average values) compared with the corresponding gravimetric results for different engine fueling (with 2 standard deviation error bar) (D-low:3Nm; Dhigh:28Nm; $1750 \mathrm{rpm} ; 28^{\circ} \mathrm{bTDC} ; 0.6 \mathrm{~kg} / \mathrm{hr}$ pilot for dual fueling). 